\title{
Composição Mineral das Pastagens das Regiões Norte e Noroeste do Estado do Rio de Janeiro. 1. Cálcio, Fósforo, Magnésio, Potássio, Sódio e Enxofre ${ }^{1}$
}

\section{Fernando Luiz Henriques Tebaldi², José Fernando Coelho da Silva ${ }^{3}$, Hernan Maldonado Vasquez ${ }^{4}$, José Tarcísio Lima Thiebaut ${ }^{5}$}

\begin{abstract}
RESUMO - Foram estudados os teores de $\mathrm{Ca}, \mathrm{P}, \mathrm{Mg}, \mathrm{K}$ e $\mathrm{Na}$ dos solos e os teores destes elementos e de $\mathrm{S}$ das forrageiras predominantes nas pastagens e na água, nas regiões norte e noroeste do Estado do Rio de Janeiro, nas épocas seca (junho-julho) e chuvosa (dezembro-janeiro). Foram coletadas amostras de solo, forrageiras e água em 12 diferentes locais das regiões, em áreas onde predominam pastagens, identificadas por fotos obtidas por satélite e de acordo com as diferentes características dos solos. Os teores de minerais das amostras foram determinados por espectrometria via plasma, após preparados os extratos. Os níveis de $\mathrm{P}$, K e Na nos solos foram muito baixos, bem como os de Ca, em alguns locais, em ambas épocas do ano. Também em alguns locais, foram encontrados baixos níveis de P nas amostras de forrageiras e houve variação desses níveis com o tipo de solo. Em alguns locais os teores de Ca das forrageiras foram adequados e os níveis de $\mathrm{Mg}$, superiores às exigências de bovinos de corte em regime de pasto. Também, em ambas épocas, foram encontrados baixos níveis de $\mathrm{Na}$ nas amostras de forrageiras. Os níveis de $\mathrm{K}$ foram superiores às exigências desses animais. Somente em um local, o nível de Na na forrageira atingiu o máximo de 10\% da exigência mínima dos bovinos e os de S, exceto em dois locais foram muito baixos. Amostras de água apresentaram níveis de Ca superiores a $70 \mathrm{mg} / \mathrm{L}$ e Na acima de $55,1 \mathrm{mg} / \mathrm{L}$, mas os valores médios na maioria dos locais, foram muito baixos. Os teores médios de Na das águas foram quatro vezes superiores às médias encontradas nos Estados Unidos, os de $\mathrm{K}$ em alguns locais variaram de 2 a 6 vezes e os de $\mathrm{S}$ foram muito baixos.
\end{abstract}

Palavras-chave: água, forrageira, mineral, pastagem, solo

\section{Mineral Composition of Pastures in the North and Northwest Regions of Rio de Janeiro State. 1. Calcium, Phosphorus, Magnesium, Potassium, Sodium and Sulfur}

\begin{abstract}
The amount of $\mathrm{Ca}, \mathrm{P}, \mathrm{Mg}, \mathrm{K}$ and $\mathrm{Na}$ of the soils, and the levels of these elements and $\mathrm{S}$ of the forages predominant in the pastures and water, were studied in the North and Northwest regions of Rio de Janeiro State, in the dry (June-July) and rainy (December-January) seasons. Samples were collected from soil, forages and water from 12 different places of the regions, in predominant grazing areas, as showed by satellite photography and according to different soil characteristics. The mineral contents of the sample extracts were determined by spectrometry, on an inductive plasma emission source apparatus. The amount of $\mathrm{P}, \mathrm{K}$ and Na in the soils were very low as well as for those of $\mathrm{Ca}$ in some places, in the dry and rainy seasons. Also, low levels of $\mathrm{P}$ were found in forage samples at some places and the forage $\mathrm{P}$ levels changed with the soil type. In some places, forage Ca levels were adequate and forage $\mathrm{Mg}$ levels were higher for the grazing beef cow requirements. Also, in both seasons low levels of $\mathrm{Na}$ were detected in the forage samples. The forage levels of $\mathrm{K}$ were higher for the requirements of these animals. Only in one place the forage Na content reached the maximum of $10 \%$ of the minimum required by these animals and forage $\mathrm{S}$ levels except in two places were low. Samples of water showed Ca contents over $70 \mathrm{mg} / \mathrm{L}$ and $\mathrm{Na}$ over $55,1 \mathrm{mg} / \mathrm{L}$, but the mean values in most of the places were very low. The mean Na contents of water were found to be four times higher than those found in USA, those of $\mathrm{K}$ in some places ranged from two to six times and the $\mathrm{S}$ contents were very low.
\end{abstract}

Key Words: forage, mineral, pasture, soil, water

\section{Introdução}

Nem sempre as deficiências minerais das pastagens mostram sintomas drásticos e definidos nos animais, mas, comumente, o que se observa são deficiências marginais com sintomas subclínicos inca- pazes de serem facilmente identificados. Esse fato, além de dificultar os estudos, torna o problema às vezes mais sério, visto que os prejuízos sobre o crescimento, a produtividade e saúde dos rebanhos escapam à observação do criador.

Em contraste com o P, a deficiência de $\mathrm{Ca}$ em

\footnotetext{
${ }^{1}$ Parte da Dissertação de Mestrado apresentada pelo primeiro autor, à Universidade Estadual do Norte Fluminense, Campos dos Goytacazes, RJ.

${ }^{2}$ Zootecnista, UFV, MS em Produção Animal, CCTA, UENF.

3 Docente LZNA, CCTA, UENF, Bolsista do CNPq. E.mail: jcoelho@uenf.br

4 Docente LZNA, CCTA, UENF, 28015-620 Campos dos Goytacazes, RJ. E.mail: hernan@uenf.br

${ }^{5}$ Laboratório de Estatística Experimental e Análise Econômica, CCTA, UENF, 28015-620 Campos dos Goytacazes, RJ.
} 


\section{4}

gado de corte é relativamente rara de ocorrer. Entretanto, já foi detectada no Pantanal do Mato Grosso e em Roraima, sendo identificada por intermédio de análises de forrageiras e de ossos de bovinos daquelas regiões (SOUSA et al., 1982). Estudos realizados por JARDIM et al. (1962) não constataram deficiência de $\mathrm{Ca}$ nas amostras de forrageiras, procedentes de diversas regiões do Brasil Central, já que estas sempre apresentaram $0,20 \%$ ou mais desse elemento na matéria seca.

A deficiência de $\mathrm{P}$ foi observada em diversas partes do mundo, e desde a primeira vez que foi descrita na África do Sul, por THEILLER et al. (1924), vem sendo a deficiência mineral mais encontrada neste planeta. ALBA e DAVIS (1957) relataram deficiência de $\mathrm{P}$ em animais em regime de pasto em vários países da América Latina, entre eles Argentina, Chile, Paraguai, Peru, Uruguai e Novo México e GIOVINI (1943), nas regiões Norte, Central e Oeste de Minas Gerais. Na região Amazônica, SUTMÖLLER et al. (1966) encontraram deficiência de $\mathrm{P}$ em solos e animais.

ALBA (1973) considerou pouco provável, em nível prático, deficiência de $\mathrm{Mg}$, pois as quantidades requeridas na dieta estão em torno de $0,05 \%$ deste elemento na matéria seca e dificilmente se encontra alimento concentrado ou forrageira com índice inferior a $0,1 \%$ de $\mathrm{Mg}$.

$\mathrm{O} \mathrm{K}$ é essencial à vida, sendo requerido em uma variedade de funções do corpo, incluindo balanço osmótico, equilíbrio ácido-base e vários sistemas enzimáticos, e no balanço hídrico corporal (CONRAD et al., 1985). As forrageiras normalmente contêm $\mathrm{K}$ suficiente para atender às necessidades nutricionais dos bovinos (Sousa, 1978, citado por SOUSA et al., 1982). Algumas informações indicam que forrageiras de inverno ou feno que foi exposto a sol e chuva podem ter níveis de $\mathrm{K}$ abaixo do adequado para boa nutrição dos bovinos (CONRAD et al., 1985).

O S é um dos elementos mais abundantes no mundo, entretanto, a deficiência de aminoácidos contendo $\mathrm{S}$ é um dos problemas mundiais em nutrição animal. O S é bem conhecido como parte dos aminoácidos metionina e cistina e também ocorre nos tecidos animais em vários compostos orgânicos e inorgânicos (Brow e outros em 1965, citados por SHIRLEY e MARIANTE, 1976). Estudos realizados com forragens da região Norte de São Paulo, em cinco períodos do ano, por POSSENTI et al. (1992), mostram que os teores de $\mathrm{S}$ atendem os requerimentos mínimos necessários para crescimento e acaba- mento de bovinos, pois, segundo o NATIONAL RESEARCH COUNCIL - NRC (1984), os níveis de $S$ na matéria seca devem estar entre 0,08 e $0,15 \%$.

De modo geral, as pastagens brasileiras apresentam baixos níveis de $\mathrm{Na}$, sendo capazes de atender entre 5 e $30 \%$ das exigências mínimas de pastejo (Conrad et al., 1978, citados por SOUSA et al., 1982).

A água é um nutriente essencial para os animais, mas não constitui uma fonte de elementos inorgânicos para os animais, embora elementos essenciais ocorram na água em quantidades variadas. Os elementos mais abundantes na água são sódio, cálcio e magnésio, que ocorrem nas formas de cloreto, carbonato, bicarbonato e sulfato. As regiões litorâneas são mais propensas a apresentarem águas mais ricas nos elementos inorgânicos. A maioria das espécies animais pode tolerar água com um total de sais dissolvidos de até $3000 \mathrm{mg}$ por litro. No entanto, as chamadas águas salobras interferem no consumo de suplementos minerais dos ruminantes; portanto, o conhecimento do teor de minerais na água disponível para o rebanho também é importante (MAYNARD et al., 1979).

Este trabalho foi conduzido para determinar os teores de $\mathrm{Ca}, \mathrm{P}, \mathrm{Mg}, \mathrm{K}$ e $\mathrm{Na}$ nos solos, e os teores destes elementos e do $\mathrm{S}$ nas forrageiras e na água, bem como suas variações estacionais, e confrontálas com as exigências de bovinos de corte.

\section{Material e Métodos}

Utilizando-se fotos de satélite e com base nas características edafológicas do solo e sua distribuição espacial, foram identificados 12 pontos com maior representatividade possível dos tipos de solo e pastagens das regiões Norte e Noroeste do Estado do Rio de Janeiro (Figura 1). Foram determinadas duas épocas bem distintas do ano, junho e julho (seca) e dezembro e janeiro (chuva), para se fazer a coleta de amostras do solo, forragem e água em cada ponto dos 12 acima mencionados.

Para cada ponto identificado, nas duas épocas definidas, foram coletadas seis amostras compostas de solo, três amostras de forrageiras e uma amostra de água. As amostras de solo foram coletadas com trado de aço inox e cada amostra composta foi constituída de cinco amostras simples. Das seis amostras compostas para cada ponto identificado, três foram da profundidade $0-20 \mathrm{~cm}$ e três da profundidade de $20-40 \mathrm{~cm}$.

As coletas de amostras de forragens foram feitas nos mesmos pontos das amostragens de solo, também 


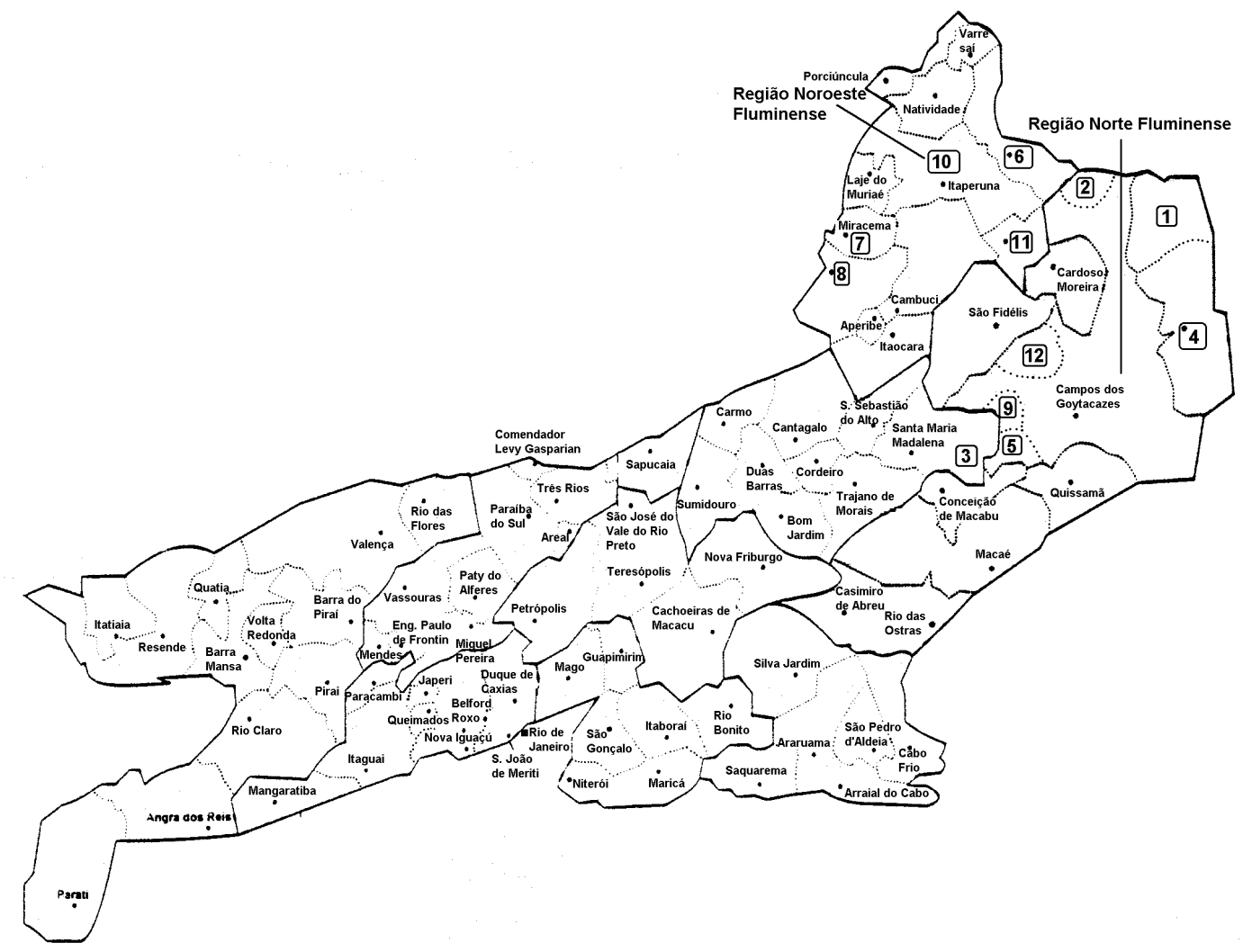

Figura 1 - São Francisco de Itabapoana; 2 - Campos-Santa Maria; Santa Maria Madalena; 4 - São João da Barra; 5 - Campos - Carvão; 6 - Bom Jesus de Itabapoana; 7 - Miracema; 8 - Santo Antonio de Pádua; 9 -Campos-Caxeta; 10 - Itaperuna; 11 - Italva; 12 - Campos-Itereré.

Figure 1 - São Francisco de Itabapoana; 2 - Campos-Santa Maria; Santa Maria Madalena; 4 - São João da Barra; 5 - Campos - Carvão; 6 - Bom Jesus de Itabapoana; 7 - Miracema; 8 - Santo Antonio de Pádua; 9 -Campos-Caxeta; 10 - Itaperuna; 11 - Italva; 12 - CamposItereré.

em diferentes faixas da pastagem. Cada amostra com aproximadamente $300 \mathrm{~g}$ do material in natura foi coletada com tesourão de aço, em altura compatível com o pastoreio dos animais.

As amostras de água foram coletadas em recepientes de vidro $(250 \mathrm{~mL})$ de acordo com a disponibilidade e acesso do gado ao bebedouro nas áreas selecionadas (rio, poço, tanques etc). Antes das análises dos minerais, cada amostra foi filtrada em papel Whatman 40. Os processamentos das amostras de forrageiras e água foram feitos no Laboratório de Zootecnia e Nutrição Animal, CCTA, UENF. O preparo das amostras de solos foi feito nos Laboratórios de Solos da UENF e da Fundação Norte Fluminense de Desenvolvimento Regional (FUNDENOR).

Para o preparo das amostras de solos, utilizou-se o método Melic e, após descanso de uma noite, pipetaram-se $50 \mathrm{~mL}$ da solução sobrenadante de cada amostra. Nas amostras de solo devidamente processadas, foram determinados $\mathrm{Ca}, \mathrm{P}, \mathrm{Mg}, \mathrm{K}$ e
Na por leitura direta via plasma no Laboratório da ARACRUZ Celulose S.A., no aparelho ICAP $61 \mathrm{E}$ PURGE (Inductively Coupled Plasma Emission Source), Thermo Jarrell Ash, por rádio frequência a $600^{\circ} \mathrm{K}$, com Argônio, para estabilizar a nebulização das amostras.

As amostras de forragens foram colocadas em sacos de papel numerados, submetidos à pre-secagem a $60^{\circ} \mathrm{C}$ e trituradas em moinho com peneira de 40 mesh. Após, foi feita a determinação da matéria seca em estufa a $105^{\circ} \mathrm{C}$. A solução mineral destas amostras foi obtida por digestão nitro-perclórica, conforme SILVA (1990). A vidraria utilizada para o preparo das amostras foi lavada com detergente neutro e água deionizada. Nas forrageiras, foram analisados os teores de $\mathrm{Ca}, \mathrm{P}, \mathrm{Mg}, \mathrm{K}, \mathrm{S}$ e Na. À semelhança das análises do solo, a determinação dos minerais nas amostras de forragens foi feita via plasma por leitura direta no Laboratório da ARACRUZ Celulose S.A., no mesmo aparelho descrito para as análises de solos.

Após as etapas anteriormente efetuadas na UENF, 
as amostras de água foram levadas para o Laboratório da ARACRUZ Celulose S.A. e submetidas à acidificação até $\mathrm{pH} 3,0$ com solução fatorada de $\mathrm{HCl}$ $0,025 \mathrm{~N}$, sendo analisados os mesmos elementos dosados nas forrageiras.

O delineamento experimental foi inteiramente casualisado, em parcelas subdivididas, tanto para as variáveis de forrageiras, quanto para as de solos. Nas análises estatísticas referentes às forrageiras, os locais constituíram as parcelas e as épocas, as subparcelas. Nas análises estatísticas referentes à composição dos solos, os locais constituíram as parcelas; as épocas, as subparcelas; e dentro destas, as profundidades. Os teores dos elementos inorgânicos nos solos e nas forrageiras, foram analisados por meio do procedimento GLM (SAS, 1990). As médias, quando apresentaram diferenças significativas, foram comparadas pelo teste de F e de Ducan no caso de $\mathrm{P}$ no solo, a 5\%. Também foram feitos estudos de correlação entre os níveis médios presentes nas forrageiras e nos solos.

Os resultados referentes às análises das forrageiras foram agrupados em função do comportamento, de uma época para outra, em crescente, decrescente e de pequena variação.

Os níveis presentes nas forrageiras foram confrontados com as exigências e, ou, níveis tóxicos para bovinos, a fim de se detectar adequabilidade ou não desses elementos.

\section{Resultados e Discussão}

Os locais das regiões Norte e Noroeste do Estado do Rio de Janeiro, identificados por foto do satélite, onde predominam áreas de pastagens, foram: 1- São Francisco do Itabapoana, 2- Campos-Santa Maria, 3Santa Maria Madalena, 4- São João da Barra, 5Campos-Carvão, 6- Bom Jesus do Itabapoana, 7Miracema, 8-Santo Antônio de Pádua, 9- CamposCaxeta, 10- Itaperuna, 11- Italva, 12- Campos-Itereré (Figura 1). Os respectivos tipos de solos predominantes nestes locais onde foram coletadas as amostras foram: 1- Podzólico vermelho amarelo distrófico textura média/argila; 2- Latossolo vermelho amarelo distrófico textura argila; 3- Latossolo vermelho amarelo álico, textura argilosa; 4- Areia quartzoza distrófico; 5- Aluvial eutrófico, textura argilosa; 6Podzólico vermelho escuro, textura média/argila; 7 Cristalino latossolo vermelho amarelo álico, textura argilosa; 8- Terra roxa estruturada latossólica, eutrófica textura argilosa; 9- Latossolo amarelo álico textura, média/argila; 10- Brunizem avermelhado, textura média/argila; 11- Podzólico vermelho escuro, textura média/argila; 12- Gley pouco húmico distrófico, textura média/argila.

A espécie forrageira predominante nos locais $1 \mathrm{e}$ 9 foi o capim-braquiária (Brachiaria decumbens, Staff); nos locais 2, 6, 7, 8 e 11, o capim-braquiarão (Brachiaria brizantha, Staff); no local 3, o capimbraquiária humidícula (Brachiaria humidicola, Schweickerdt); no local 4, o capim-furachão (Panicum repens, L); nos locais 5 e 12, o capimangola (Brachiaria purpuracens, Henr.); e no local 10, o capim-colonião (Panicum maximum, Jacq)

Os teores de Ca nos solos (Tabela 1) variaram em função dos locais e das profundidades $(\mathrm{P}<0,01)$ estudadas, constatando-se também interação de local e profundidade e de local e época. Somente em Itaperuna, em ambas profundidades, os níveis foram menores na época chuvosa. Este comportamento também foi observado no local 5, na profundidade 20 $\mathrm{cm}$, e situação inversa ocorreu no local 8 , na profundidade de $40 \mathrm{~cm}$.

O município de Itaperuna é o único que, segundo a classificação de GUIMARÃES et al. (1980), apresenta alto teor de Ca no solo. Os locais 2, 11, 8, 5, 1, 6 e 12 foram classificados como de teor médio de $\mathrm{Ca}$ no solo, enquanto os locais 7, 9, 4 e 3, de baixo teor deste elemento em seus solos. S.M. Madalena foi o local onde se observou o mais baixo teor de $\mathrm{Ca}$ nos solos pesquisados.

Os teores de Ca nas forrageiras (Tabela 2) variaram em função dos locais $(\mathrm{P}<0,05)$ e das épocas estudadas, havendo também interação $(\mathrm{P}<0,01)$ de local e época. Em cinco dos locais, estes teores foram mais altos na época seca $(\mathrm{P}<0,05)$, reduzindo a praticamente à metade de seu valor na época chuvosa (comportamento decrescente). O inverso aconteceu em Bom Jesus do Itabapoana, porém em outros seis locais os níveis não diferiram $(\mathrm{P}>0,05)$ em função das épocas, sendo enquadrados no comportamento de pequena variação. O teor médio mais alto $(0,83 \%)$ foi observado em Itaperuna, decrescendo até $0,25 \%$, em São João da Barra, mostrando reflexo dos níveis presentes no solo, tendo-se encontrado correlação $(\mathrm{r}=0,74, \mathrm{P}<0,02)$ entre os teores de $\mathrm{Ca}$ no solo e na forrageira.

SOUSA et al. (1982) encontraram deficiência de Ca em gado de corte no Pantanal do Mato Grosso e Roraima, por intermédio de análise das forrageiras locais, o que raramente ocorreu. Conforme JARDIM et al. (1962), em estudo sobre teores minerais em 
Rev. bras. zootec.

Tabela 1 - Teores médios de Ca (meq/100 g) nos solos, nas épocas seca (Ep1) e chuvosa (Ep2), nas profundidades de $20 \mathrm{~cm}$ (1) e $40 \mathrm{~cm}$ (2), nos diferentes locais e seus respectivos números de identificação $(\mathrm{N})$

Table 1 - Average Ca contents (meq/100 g) of soils, in the dry (Ep1) and rainy (Ep2) seasons, in the depths of $20 \mathrm{~cm}$ (1) and $40 \mathrm{~cm}$ (2) in the different places and the respective identification numbers $(N)$

\begin{tabular}{|c|c|c|c|c|c|}
\hline $\begin{array}{l}\text { Local } \\
\text { Place } \\
\end{array}$ & $\mathrm{N}$ & $\begin{array}{c}\text { Profundidade } \\
\text { Depth }\end{array}$ & Ep 1 & Ep 2 & $\begin{array}{c}\text { Média } \\
\text { Mean }\end{array}$ \\
\hline \multirow[t]{2}{*}{ Itaperuna } & 10 & 1 & $7,67^{b}$ & $4,67^{\mathrm{a}}$ & 6,17 \\
\hline & & 2 & $6,67^{b}$ & $4,33^{\mathrm{a}}$ & 5,50 \\
\hline \multirow[t]{2}{*}{ Italva } & 11 & 1 & $4,0^{\mathrm{a}}$ & $2,33^{\mathrm{a}}$ & 3,67 \\
\hline & & 2 & $3,67^{\mathrm{a}}$ & $2,33^{\mathrm{a}}$ & 3,00 \\
\hline \multirow[t]{2}{*}{ Campos-Carvão } & 5 & 1 & $4,00^{b}$ & $2,00^{\mathrm{a}}$ & 3,00 \\
\hline & & 2 & $2,67^{\mathrm{a}}$ & $2,00^{\mathrm{a}}$ & 2,33 \\
\hline \multirow[t]{2}{*}{ Miracema } & 7 & 1 & $1,33^{\mathrm{a}}$ & $1,00^{\mathrm{a}}$ & 1,17 \\
\hline & & 2 & $0,33^{\mathrm{a}}$ & $0,33^{\mathrm{a}}$ & 0,33 \\
\hline \multirow[t]{2}{*}{ S.A.Pádua } & 8 & 1 & $2,67^{\mathrm{a}}$ & $4,00^{\mathrm{a}}$ & 3,33 \\
\hline & & 2 & $2,00^{\mathrm{a}}$ & $4,33^{b}$ & 3,17 \\
\hline \multirow[t]{2}{*}{ B.J.Itabapoana } & 6 & 1 & $2,00^{\mathrm{a}}$ & $2,00^{\mathrm{a}}$ & 2,00 \\
\hline & & 2 & $1,67^{\mathrm{a}}$ & $2,00^{\mathrm{a}}$ & 1,83 \\
\hline \multirow[t]{2}{*}{ Campos-Itereré } & 12 & 1 & $1,00^{\mathrm{a}}$ & $2,00^{\mathrm{a}}$ & 1,50 \\
\hline & & 2 & $1,00^{\mathrm{a}}$ & $2,00^{\mathrm{a}}$ & 1,50 \\
\hline \multirow[t]{2}{*}{ Campos-Caxeta } & 9 & 1 & $1,00^{\mathrm{a}}$ & $1,33^{\mathrm{a}}$ & 1,17 \\
\hline & & 2 & $0,33^{\mathrm{a}}$ & $1,00^{\mathrm{a}}$ & 0,67 \\
\hline \multirow[t]{2}{*}{ S.J.Barra } & 4 & 1 & $1,00^{\mathrm{a}}$ & $1,00^{\mathrm{a}}$ & 1,00 \\
\hline & & 2 & $0,33^{\mathrm{a}}$ & $0,67^{\mathrm{a}}$ & 0,50 \\
\hline \multirow{2}{*}{ S.M.Madalena } & 3 & 1 & $0,33^{\mathrm{a}}$ & $1,00^{\mathrm{a}}$ & 0,67 \\
\hline & & 2 & $0,33^{\mathrm{a}}$ & $0,33^{\mathrm{a}}$ & 0,33 \\
\hline \multirow[t]{2}{*}{ Campos-S.Maria } & 2 & 1 & $4,67^{\mathrm{a}}$ & $5,33^{\mathrm{a}}$ & 5,00 \\
\hline & & 2 & $2,67^{\mathrm{a}}$ & $2,67^{\mathrm{a}}$ & 2,67 \\
\hline \multirow{2}{*}{ S.F.Itabapoana } & 1 & 1 & $1,67^{\mathrm{a}}$ & $2,00^{\mathrm{a}}$ & 1,83 \\
\hline & & 2 & $2,67^{\mathrm{a}}$ & $2,00^{\mathrm{a}}$ & 2,33 \\
\hline
\end{tabular}

Dentro de cada local e para cada profundidade, médias seguidas de mesma letra não diferem, pelo teste de $\mathrm{F}$, em nível de $5 \%$ de probabilidade.

Within each place and for each depth, means followed by the same letter do not differ, by $F$ test, at $5 \%$ level of probability.

Tabela 2 - Teores médios de Ca (\% na MS) das forrageiras, nas épocas seca (Ep1) e chuvosa (Ep2), nos diferentes locais, e seus respectivos números de identificação $(\mathrm{N})$

Table 2 - Average Ca contents (\% in dry matter) of forages, in the dry (Ep1) and rainy (Ep2) seasons, in the different places and the respective identification numbers $(N)$

\begin{tabular}{lccccc}
\hline $\begin{array}{l}\text { Comportamento } \\
\text { Behavior }\end{array}$ & $\mathrm{N}$ & $\begin{array}{c}\text { Local } \\
\text { Place }\end{array}$ & Ep 1 & Ep 2 & $\begin{array}{c}\text { Média } \\
\text { Mean }\end{array}$ \\
\hline Decrescente & 10 & Itaperuna & $1,01^{\mathrm{b}}$ & $0,64^{\mathrm{a}}$ & 0,83 \\
Decreasing & 2 & Campos-S.Maria & $0,86^{\mathrm{b}}$ & $0,45^{\mathrm{a}}$ & 0,66 \\
& 7 & Miracema & $0,89^{\mathrm{b}}$ & $0,27^{\mathrm{a}}$ & 0,58 \\
& 11 & Italva & $0,74^{\mathrm{b}}$ & $0,35^{\mathrm{a}}$ & 0,55 \\
& 8 & S.A.Pádua & $0,68^{\mathrm{b}}$ & $0,26^{\mathrm{a}}$ & 0,47 \\
\hline Pequena varição & 3 & S.M.Madalena & $0,58^{\mathrm{a}}$ & $0,33^{\mathrm{a}}$ & 0,45 \\
Small variation & 12 & Campos-Itereré & $0,45^{\mathrm{a}}$ & $0,29^{\mathrm{a}}$ & 0,37 \\
& 9 & Campos-Caxeta & $0,34^{\mathrm{a}}$ & $0,40^{\mathrm{a}}$ & 0,37 \\
& 1 & S.F.Itabapoana & $0,48^{\mathrm{a}}$ & $0,24^{\mathrm{a}}$ & 0,36 \\
& 5 & Campos-Carvão & $0,40^{\mathrm{a}}$ & $0,29^{\mathrm{a}}$ & 0,34 \\
\hline Crescente & 4 & S.J.Barra & $0,33^{\mathrm{a}}$ & $0,17^{\mathrm{a}}$ & 0,25 \\
Increasing & 6 & B .J.Itabapoana & $0,35^{\mathrm{a}}$ & $0,68 \mathrm{~b}^{\mathrm{b}}$ & 0,51 \\
\hline
\end{tabular}

Dentro de cada local, médias seguidas de mesma letra não diferem, pelo teste $\mathrm{F}$, em nível de $5 \%$ de probabilidade.

Within each place, means followed by the same letter do not differ, by $F$ test, at $5 \%$ level of probability. 
608

diversas forrageiras procedentes do Brasil Central, não foi detectada deficiência de Ca nas forrageiras daquela região, já que em todas os teores de Ca foram iguais ou superiores a $0,20 \%$ na matéria seca, o que assemelha aos resultados médios obtidos no presente trabalho, segundo a Tabela 2, com exceção da localidade de São João da Barra, onde a forrageira apresentou $0,17 \%$ na MS.

Conforme o NRC (1996), a exigência de Ca para bovino de $300 \mathrm{~kg}$ de peso vivo com ganho de $0,5 \mathrm{~kg} / \mathrm{dia}$, é de $0,12 \%$ de Ca na MS da dieta, o que leva a se afirmar que tal exigência é atendida em todos os locais e épocas estudados, conforme a Tabela 2. Para ganho de 1,0 kg/dia, o NRC (1996) recomenda $0,23 \%$ de Ca na MS; neste caso, somente a forrageira do solo arenoso de São João da Barra no período das chuvas não atenderia tal exigência.

$\mathrm{O}$ teor de $\mathrm{P}$ nos solos (Tabela 3 ) foi diferente nos locais estudados $(\mathrm{P}<0,05)$, apresentando também interação de local e profundidade $(\mathrm{P}<0,01)$.

Admitindo-se que o teor de $10 \mathrm{ppm}$ de $\mathrm{P}$, como valor representativo de fertilidade média nos solos (GUIMARÃES et al., 1980), pode-se concluir que somente os solos do município de Campos nas regiões de S.Maria (local 2), com teor médio de 18,08 ppm, e Itereré (local 12), com 16,00 ppm, estão acima dessa média. No caso de Campos-Carvão, com 5,41 ppm, e S.J.Barra, com 4,33 ppm, são considerados excessivamente pobres deste mineral em seus solos.

Em várias regiões do Brasil, têm sido encontra- das pronunciadas deficiências deste mineral em solos, forragens e animais, o que se comprova nos trabalhos de GIOVINI (1943), nas regiões Norte, Central e Oeste de Minas Gerais; SUTMOLLER et al. (1966), na região Amazônica; e TEIXEIRA et al. (1971), na região Sul de Goiás, entre outros pesquisadores.

Os teores de $\mathrm{P}$ nas forrageiras (Tabela 4) apresentaram variações $(\mathrm{P}<0,01)$ em função dos locais e das épocas, bem como interação desses dois fatores. Em dois locais, apresentaram-se menores na época chuvosa em relação à época seca $(\mathrm{P}<0,05)$. Em outros sete locais estudados, os teores médios de $\mathrm{P}$ foram menores $(\mathrm{P}<0,05)$ na época seca, quando comparados com a época chuvosa (comportamento crescente) e em outros três locais, a variação entre épocas não foi significativa, sendo classificados como de pequena variação. $O$ coeficiente de correlação entre os níveis de $\mathrm{P}$ no solo e na forrageira foi $\mathrm{r}=0,59$ $(\mathrm{P}<0,02)$. Os níveis de $\mathrm{P}$ nas forrageiras estão abaixo de $0,12 \%$ na MS, em São João da Barra, Santa Maria Madalena e Santo Antônio de Pádua, na época seca, constatando-se valores elevados em algumas regiões. Conforme o NRC (1989), a exigência de P para bovinos em crescimento e engorda varia de 0,12 a $0,30 \%$ na MS da dieta.

Os teores de $\mathrm{Mg}$ nos solos (Tabela 5) variaram em função dos locais $(\mathrm{P}<0,01)$ e das profundidades $(\mathrm{P}<0,05)$, ocorrendo também interação de local e época $(\mathrm{P}<0,01)$, entretanto, não se constatou diferença entre época. Em

Tabela 3 - Teores médios de $P$ (ppm) nos solos, nas épocas seca (Ep1) e chuvosa (Ep2), à profundidade de 20 (P1) e $40 \mathrm{~cm}$ (P2), nos diferentes locais, e seus respectivos números de identificação $(\mathrm{N})$

Table 3 - $\quad$ Average $P$ contents (meq/100 g) of soils, in the dry (Ep1) and rainy (Ep2) seasons, in the depths of 20 (1) and $40 \mathrm{~cm}$ (2) in the different places and the respective identification numbers $(N)$

\begin{tabular}{lrrrrrrc}
\hline $\begin{array}{l}\text { Local } \\
\text { Place }\end{array}$ & $\mathrm{N}$ & $\mathrm{Ep} 1$ & $\mathrm{Ep} 2$ & $\mathrm{P} 1$ & $\mathrm{P} 2$ & $\begin{array}{c}\text { Média } \\
\text { Mean }\end{array}$ \\
\hline S.F.Itabapoana & 1 & 3,00 & 2,50 & 3,17 & 2,33 & 2,75 & $\mathrm{CD}$ \\
Italva & 11 & 2,50 & 1,00 & 1,50 & 2,00 & 1,75 & $\mathrm{D}$ \\
S.M.Madalena & 3 & 2,00 & 1,00 & 1,50 & 1,50 & $(1,50)$ & \\
Campos-Carvão & 5 & 5,17 & 5,67 & 7,67 & 3,17 & 5,41 & $\mathrm{~B}$ \\
Campos-Caxeta & 9 & 1,83 & 3,50 & 3,83 & 1,50 & 2,67 & $\mathrm{CD}$ \\
B.J.Itabapoana & 6 & 1,67 & 1,33 & 1,50 & 1,00 & 1,25 & $\mathrm{D}$ \\
Miracema & 7 & 1,17 & 1,00 & 1,17 & 1,00 & 1,08 & $\mathrm{D}$ \\
S.A.Pádua & 8 & 1,00 & 1,00 & 1,00 & 1,00 & $(1,00)$ & \\
Campos-S.Maria & 2 & 19,83 & 16,33 & 27,50 & 8,67 & $(18,08)$ & \\
Campos-Itereré & 12 & 16,00 & 15,33 & 13,33 & 18,67 & 16,00 & $\mathrm{~A}$ \\
S.J.Barra & 4 & 4,33 & 4,33 & 4,00 & 4,67 & 4,33 & $\mathrm{BC}$ \\
Itaperuna & 10 & 2,16 & 6,50 & 4,50 & 4,16 & 4,34 & $\mathrm{BC}$ \\
\hline
\end{tabular}

Letras maiúsculas comparam médias nas colunas para locais, pelo teste de Duncan a $5 \%$.

( ) Média sem variação.

Capital letters compare means in the columns, by Duncan test at $5 \%$ level.

() Means without variation. 
Rev. bras. zootec.

Tabela 4 - Teores médios de P (\% na MS) das forrageiras, nas épocas seca (Ep1) e chuvosa (Ep2) nos diferentes locais, e seus respectivos números de identificação $(\mathrm{N})$

Table 4 - Average $P$ contents (\% in dry matter) of forages, in the dry (Ep1) and rainy (Ep2) seasons, in the different places and the respective identification numbers $(N)$

\begin{tabular}{lrllcc}
\hline $\begin{array}{l}\text { Comportamento } \\
\text { Behavior }\end{array}$ & $\mathrm{N}$ & \multicolumn{1}{c}{$\begin{array}{c}\text { Local } \\
\text { Place }\end{array}$} & Ep 1 & Ep 2 & $\begin{array}{c}\text { Média } \\
\text { Mean }\end{array}$ \\
\hline $\begin{array}{l}\text { Decrescente } \\
\text { Decreasing }\end{array}$ & 2 & Campos-S.Maria & $0,40^{\mathrm{b}}$ & $0,31^{\mathrm{a}}$ & 0,35 \\
\hline Crescente & 12 & Campos-Itereré & $0,33^{\mathrm{b}}$ & $0,24^{\mathrm{a}}$ & 0,28 \\
Increasing & 5 & Campos-Carvão & $0,38^{\mathrm{a}}$ & $0,45^{\mathrm{b}}$ & 0,42 \\
& 9 & Campos-Caxeta & $0,12^{\mathrm{a}}$ & $0,38^{\mathrm{b}}$ & 0,25 \\
& 10 & Itaperuna & $0,17^{\mathrm{a}}$ & $0,27^{\mathrm{b}}$ & 0,22 \\
& 6 & B.J.Itabapoana & $0,13^{\mathrm{a}}$ & $0,33^{\mathrm{b}}$ & 0,22 \\
& 8 & S.A.Pádua & $0,11^{\mathrm{a}}$ & $0,24^{\mathrm{b}}$ & 0,18 \\
& 3 & S.M.Madalena & $0,09^{\mathrm{a}}$ & $0,14^{\mathrm{b}}$ & 0,12 \\
\hline Pequena variação & 1 & S.J.Barra & $0,07^{\mathrm{a}}$ & $0,16^{\mathrm{b}}$ & 0,12 \\
Small variation & 7 & S.F.Itabapoana & $0,23^{\mathrm{a}}$ & $0,19^{\mathrm{a}}$ & 0,21 \\
& 11 & Miracema & $0,17^{\mathrm{a}}$ & $0,13^{\mathrm{a}}$ & 0,15 \\
& Italva & $0,15^{\mathrm{a}}$ & $0,17^{\mathrm{a}}$ & 0,16 \\
\hline
\end{tabular}

Dentro de cada local, médias seguidas de mesma letra não diferem, pelo teste de $\mathrm{F}$, a $5 \%$ de probabilidade. Within each place, means followed by the same letter do not differ, by $F$ test, at $5 \%$ level of probability.

Tabela 5 - Teores médios de Mg (meq/100g) nos solos, nas épocas seca (Ep1) e chuvosa (Ep2) nos diferentes locais e seus respectivos números de identificação $(\mathrm{N})$

Table 5 - $\quad$ Average $\mathrm{Mg}$ contents (meq/100g) of soils, in the dry (Ep1) and rainy (Ep2) seasons, in the different places and the respective identification numbers $(N)$

\begin{tabular}{lcccc}
\hline $\begin{array}{l}\text { Local } \\
\text { Place }\end{array}$ & $\mathrm{N}$ & $\mathrm{Ep} 1$ & $\mathrm{Ep} 2$ & $\begin{array}{c}\text { Média } \\
\text { Mean }\end{array}$ \\
\hline Italva & 11 & $3,00 \mathrm{~b}$ & $2,00^{\mathrm{a}}$ & 2,50 \\
Campos-Itereré & 12 & $2,17^{\mathrm{a}}$ & $1,50^{\mathrm{a}}$ & 1,83 \\
Itaperuna & 10 & $2,17^{\mathrm{a}}$ & $1,33^{\mathrm{a}}$ & 1,75 \\
Campos-Caxeta & 9 & $1,00^{\mathrm{a}}$ & $0,50^{\mathrm{a}}$ & 0,75 \\
S.A.Pádua & 8 & $0,83^{\mathrm{a}}$ & $2,33^{\mathrm{b}}$ & 1,58 \\
S.F.Itabapoana & 1 & $1,17^{\mathrm{a}}$ & $1,50^{\mathrm{a}}$ & 1,33 \\
Miracema & 7 & $0,83^{\mathrm{a}}$ & $1,33^{\mathrm{a}}$ & 1,08 \\
Campos-Carvão & 5 & $4,17^{\mathrm{a}}$ & $3,50^{\mathrm{a}}$ & 3,83 \\
Campos-S.Maria & 2 & $1,83^{\mathrm{a}}$ & $1,83^{\mathrm{a}}$ & 1,83 \\
S.M.Madalena & 3 & $(1,30)$ & $(0,63)$ & $(0,97)$ \\
S.J.Barra & 4 & $0,83^{\mathrm{a}}$ & $0,67^{\mathrm{a}}$ & 0,75 \\
B.J.Itabapoana & 6 & $1,17^{\mathrm{a}}$ & $1,67^{\mathrm{a}}$ & 1,42 \\
\hline
\end{tabular}

Dentro de cada local e para cada profundidade, médias seguidas de mesma letra não diferem, pelo teste de $\mathrm{F}$, em nível de $5 \%$ de probabilidade.

Within each place and for each depth, means followed by the same letter do not differ, by $F$ test at $5 \%$ level of probability.

( ) Média sem variação.

() Mean without variation.

Italva, o teor foi menor na época chuvosa e em S.F.Itabapoana ocorreu o inverso, não havendo diferença entre épocas nas demais localidades.

Os teores de $\mathrm{Mg}$ das forrageiras variaram em função dos locais $(\mathrm{P}<0,05)$ e das épocas do ano, constatando-se também interação $(\mathrm{P}<0,01)$ de local e época. Em quatro das regiões estudadas, os teores de
$\mathrm{Mg}$ nas forrageiras (Tabela 6) decresceram $(\mathrm{P}<0,05)$ da época seca para a época chuvosa. Nos demais locais, não houve efeito das épocas do ano sobre os teores de $\mathrm{Mg}$, sendo enquadrados no grupo com comportamento de pequena variação.

Não foi encontrada correlação significativa entre níveis de $\mathrm{Mg}$ nos solos e forrageiras ( $\mathrm{r}=0,0923$, $\mathrm{P}=0,39$ ).

Os resultados obtidos, conforme Tabela 6 , confirmam ser bastante abundante o nível de $\mathrm{Mg}$ nas forrageiras, como afirmou COELHO DA SILVA (1995). Conforme ALBA (1973), é pouco provável a ocorrência de deficiência de $\mathrm{Mg}$ para bovino, já que as quantidades requeridas deste mineral na dieta estão em torno de $0,05 \%$ na MS e, neste trabalho, foram encontrados valores bem superiores, variando de 0,21 a $0,67 \%$ na MS, na época seca, e de $0,18 \%$ a $0,46 \%$ na MS, na época das chuvas. Também atende a exigência de bovinos em crescimento, conforme Thomas e Potter (1976), citados por CONRAD et al. (1985), os quais relataram que esta exigência seria de $0,10 \%$ de Mg na MS.

Considerando recomendações do NRC (1996) para bovinos em crescimento e engorda $(0,10 \%)$ e vacas de corte em gestação $(0,12 \%)$ e em lactação $(0,20 \%$ na MS), os níveis encontrados no presente trabalho atendem às exigências.

Quanto à toxidez de $\mathrm{Mg}$ várias regiões, notadamente na época seca o nível de $0,40 \%$ na MS, que segundo NRC (1996) é o nível máximo tolerável, foi ultrapassado. 
TEBALDI et al.

Tabela 6 - Teores médios de Mg (\% na MS) das forrageiras, nas épocas seca (Ep1) e chuvosa (Ep2) nos diferentes locais, e seus respectivos números de identificação $(\mathrm{N})$

Table 6 - $\quad$ Average $M g$ contents (\% in dry matter) of forages, in the dry (Ep1) and rainy (Ep2) seasons, in the different places and the respective identification numbers $(N)$

\begin{tabular}{lclccc}
\hline $\begin{array}{l}\text { Comportamento } \\
\text { Behavior }\end{array}$ & $\mathrm{N}$ & $\begin{array}{c}\text { Local } \\
\text { Place }\end{array}$ & Ep 1 & Ep 2 & $\begin{array}{c}\text { Média } \\
\text { Mean }\end{array}$ \\
\hline $\begin{array}{lclcc}\text { Decrescente } \\
\text { Decreasing }\end{array}$ & 3 & S.M.Madalena & $0,59^{\mathrm{b}}$ & $0,38^{\mathrm{a}}$ & 0,48 \\
& 7 & $\begin{array}{l}\text { Miracema } \\
0,67^{\mathrm{b}}\end{array}$ & $0,25^{\mathrm{a}}$ & 0,46 \\
& 1 & S.F.Itabapoana & $0,48^{\mathrm{b}}$ & $0,25^{\mathrm{a}}$ & 0,37 \\
\hline Pequena variação & 9 & Italva & $0,65^{\mathrm{b}}$ & $0,24^{\mathrm{a}}$ & 0,45 \\
Small variation & 6 & Campos-Caxeta & $0,33^{\mathrm{a}}$ & $0,46^{\mathrm{a}}$ & 0,39 \\
& 2 & B .J.Itabapoana & $0,28^{\mathrm{a}}$ & $0,39^{\mathrm{a}}$ & 0,34 \\
& 8 & S.A.Pádua & $0,44^{\mathrm{a}}$ & $0,33^{\mathrm{a}}$ & 0,45 \\
& 5 & Campos-Carvão & $0,37^{\mathrm{a}}$ & $0,37^{\mathrm{a}}$ & 0,37 \\
& 12 & Campos-Itereré & $0,24^{\mathrm{a}}$ & $0,24^{\mathrm{a}}$ & 0,31 \\
& 10 & Itaperuna & $0,24^{\mathrm{a}}$ & $0,24^{\mathrm{a}}$ & 0,31 \\
& 4 & S.J.Barra & $0,21^{\mathrm{a}}$ & $0,18^{\mathrm{a}}$ & 0,20 \\
\hline
\end{tabular}

Dentro de cada local, médias seguidas de mesma letra não diferem, pelo teste de F, em nível de $5 \%$ de probabilidade.

Within each place, means followed by the same letter do not differ, by $F$ test at $5 \%$ level of probability.

Os teores de $\mathrm{K}$ nos solos (Tabela 7) variaram $(\mathrm{P}<0,05)$ em função dos locais, das profundidades $(\mathrm{P}<0,01)$ e épocas $(\mathrm{P}<0,05)$. Somente em S.J. Barra, na profundidade de $40 \mathrm{~cm}$, e em Campos-Carvão, na profundidade de $20 \mathrm{~cm}$, não ocorreu diferença entre épocas. Observa-se que o município de CamposS.Maria apresentou o teor mais elevado de K no solo (164,30 meq./100 g), enquanto o solo de areia quartzoza distrófico de S.J. Barra, o menor $(24,75$ meq./100 g), considerando-se a média das duas profundidades.

Examinando os teores de $\mathrm{K}$ nos solos (Tabela 7), pode-se considerar que Miracema apresentou baixo teor deste mineral em seu solo e os locais 3, 8, 9, 6 e 10 , teor médio de $\mathrm{K}$. Os locais $2,1,11,12$ e 5 tiveram teor de $\mathrm{K}$ no solo classificado como alto, conforme proposto por GUIMARÃES et al. (1980). TOKARNIA et al. (1988) também encontraram vários resultados semelhantes aos deste estudo, em levantamentos feitos em várias regiões do Brasil.

Houve efeito de local, época do ano e interação desses fatores $(\mathrm{P}<0,01)$ sobre os teores de $\mathrm{K}$ das forrageiras (Tabela 8). Na região de S.F. do Itabapoana, o teor de $\mathrm{K}$ nas forrageiras foi menor $(\mathrm{P}<0,05)$ na época chuvosa; em outros seis locais, o comportamento foi inverso; e nos demais não foram observadas diferenças significativas entre épocas. Foi também encontrada correlação $(r=0,49, \mathrm{P}<0,05)$ entre os teores de $\mathrm{K}$ nos solos e nas forrageiras.

Comparando-se os níveis de $\mathrm{K}$ das forrageiras anali- sadas neste trabalho com as exigências deste mineral para bovinos, os resultados assemelham aos de TOKARNIA et al. (1988) e SOUSA et al. (1982), os quais afirmaram que as forragens normalmente contêm $\mathrm{K}$ suficiente para atender as necessidades nutricionais dos bovinos.

Hutcheson em 1979, citado por CONRAD et al. (1985), estimou o requerimento de K para bovinos em 0,5 a 0,8\%; a recomendação do NRC (1996) é 0,6\% na MS da dieta para gado de corte; dessa forma, as exigências podem ser atendidas em todos os locais, inclusive em São João da Barra, onde foi encontrado $0,77 \%$ de K na MS na época seca.

O nível encontrado no período chuvoso em Campos-Carvão, 4,06\% de K na MS, está acima do indicado como máximo tolerável para bovinos pelo NRC (1996), que é 3,00\% na MS.

\section{Enxofre}

Os teores de $\mathrm{S}$ das forrageiras foram influenciados pelo local $(\mathrm{P}<0,01)$, não se constatando efeito de época $(\mathrm{P}>0,05)$, porém houve interação de local e época $(\mathrm{P}<0,01)$ (Tabela 9). Em S. F. Itabapoana, o teor de $\mathrm{S}$ das forrageiras foi maior $(\mathrm{P}<0,05)$ na época seca $(0,08 \%)$ e menor na época chuvosa $(0,04 \%)$; em Campos-Caxeta e Bom Jesus Itabapoana, o comportamento foi inverso. Nos demais locais, não houve diferença nos teores entre épocas seca e chuvosa.

POSSENTI et al. (1992), em trabalhos com forrageiras na Região Norte de São Paulo, encontra- 
Rev. bras. zootec.

Tabela 7 - Teores médios de K (meq/100g) nos solos, nas épocas seca (Ep1) e chuvosa (Ep2), nas profundidades de 20 (1) e $40 \mathrm{~cm}$ (2), nos diferentes locais, e seus respectivos números de identificação $(\mathrm{N})$

Table 7 - Average K contents (meq/100g) of soils, in the dry (Ep1) and rainy (Ep2) seasons, in the depths of 20 (1) and $40 \mathrm{~cm}$ (2) in the different places and the respective identification numbers $(N)$

\begin{tabular}{|c|c|c|c|c|c|}
\hline $\begin{array}{l}\text { Local } \\
\text { Place }\end{array}$ & $\mathrm{N}$ & $\begin{array}{c}\text { Profundidade } \\
\text { Depth }\end{array}$ & Ep 1 & Ep 2 & $\begin{array}{l}\text { Média } \\
\text { Mean }\end{array}$ \\
\hline Miracema & 7 & $\begin{array}{l}1 \\
2\end{array}$ & $\begin{array}{l}42,67^{b} \\
17,67^{b}\end{array}$ & $\begin{array}{l}25,33^{\mathrm{a}} \\
15,67^{\mathrm{a}}\end{array}$ & $\begin{array}{l}34,00 \\
16,67\end{array}$ \\
\hline Campos-Carvão & 5 & $\begin{array}{l}1 \\
2\end{array}$ & $\begin{array}{r}126,33^{\mathrm{b}} \\
56,33^{\mathrm{a}}\end{array}$ & $\begin{array}{l}80,67^{\mathrm{a}} \\
57,33^{\mathrm{a}}\end{array}$ & $\begin{array}{r}103,50 \\
56,83\end{array}$ \\
\hline S.M.Madalena & 3 & $\begin{array}{l}1 \\
2\end{array}$ & $\begin{array}{l}38,33^{\mathrm{b}} \\
38,33^{\mathrm{b}}\end{array}$ & $\begin{array}{l}37,00^{\mathrm{a}} \\
18,00^{\mathrm{a}}\end{array}$ & $\begin{array}{l}37,67 \\
28,17\end{array}$ \\
\hline Campos-S.Maria & 2 & $\begin{array}{l}1 \\
2\end{array}$ & $\begin{array}{l}186,00^{\mathrm{b}} \\
144,67^{\mathrm{a}}\end{array}$ & $\begin{array}{l}139,33^{\mathrm{a}} \\
187,33^{\mathrm{b}}\end{array}$ & $\begin{array}{l}162,67 \\
166,00\end{array}$ \\
\hline S.F.Itabapoana & 1 & $\begin{array}{l}1 \\
2\end{array}$ & $\begin{array}{r}160,33^{\mathrm{b}} \\
71,33^{\mathrm{b}}\end{array}$ & $\begin{array}{l}141,00^{\mathrm{a}} \\
100,67\end{array}$ & $\begin{array}{r}150,67 \\
86,00\end{array}$ \\
\hline B.J.Itabapoana & 6 & $\begin{array}{l}1 \\
2\end{array}$ & $\begin{array}{l}52,67^{\mathrm{a}} \\
34,33^{\mathrm{b}}\end{array}$ & $\begin{array}{l}63,67^{\mathrm{b}} \\
21,00^{\mathrm{a}}\end{array}$ & $\begin{array}{l}58,17 \\
27,67\end{array}$ \\
\hline S.A.Pádua & 8 & $\begin{array}{l}1 \\
2\end{array}$ & $\begin{array}{l}46,33^{\mathrm{b}} \\
14,00^{\mathrm{a}}\end{array}$ & $\begin{array}{l}41,33^{\mathrm{a}} \\
34,67^{\mathrm{b}}\end{array}$ & $\begin{array}{l}43,83 \\
24,33\end{array}$ \\
\hline Italva & 11 & $\begin{array}{l}1 \\
2\end{array}$ & $\begin{array}{l}70,33^{\mathrm{a}} \\
55,67^{\mathrm{a}}\end{array}$ & $\begin{array}{r}132,00^{\mathrm{b}} \\
84,00^{\mathrm{b}}\end{array}$ & $\begin{array}{r}101,17 \\
69,83\end{array}$ \\
\hline Campos-Itereré & 12 & $\begin{array}{l}1 \\
2\end{array}$ & $\begin{array}{l}44,67^{\mathrm{a}} \\
30,00^{\mathrm{a}}\end{array}$ & $\begin{array}{r}99,67^{\mathrm{b}} \\
163,33^{\mathrm{b}}\end{array}$ & $\begin{array}{l}72,17 \\
96,67\end{array}$ \\
\hline Itaperuna & 10 & $\begin{array}{l}1 \\
2\end{array}$ & $\begin{array}{l}28,00^{\mathrm{a}} \\
25,33^{\mathrm{a}}\end{array}$ & $\begin{array}{l}59,33^{\mathrm{b}} \\
69,00^{\mathrm{b}}\end{array}$ & $\begin{array}{l}43,67 \\
47,17\end{array}$ \\
\hline Campos-Caxeta & 9 & $\begin{array}{l}1 \\
2\end{array}$ & $\begin{array}{r}34,67^{\mathrm{a}} \\
7,67^{\mathrm{a}}\end{array}$ & $\begin{array}{l}58,33^{\mathrm{b}} \\
58,33^{\mathrm{b}}\end{array}$ & $\begin{array}{l}46,50 \\
33,00\end{array}$ \\
\hline S.J.Barra & 4 & $\begin{array}{l}1 \\
2\end{array}$ & $\begin{array}{l}25,33^{\mathrm{a}} \\
15,67^{\mathrm{a}}\end{array}$ & $\begin{array}{l}34,00^{\mathrm{a}} \\
24,00^{\mathrm{b}}\end{array}$ & $\begin{array}{l}29,67 \\
19,83\end{array}$ \\
\hline
\end{tabular}

Dentro de cada local e para cada profundidade, médias seguidas de mesma letra não diferem, pelo teste de $\mathrm{F}$, a $5 \%$ de probabilidade.

Within each place and for each depth, means followed by the same letter do not differ, by F test, at $5 \%$ level of probability.

Tabela 8 - Teores médios de K(\% na MS) das forrageiras nasépocas seca (Ep1) e chuvosa (Ep2) nos diferentes locais, e seus respectivos números de identificação $(\mathrm{N})$

Table 8 - Average K contents (\% in dry matter) of forages, in the dry (Ep1) and rainy (Ep2) seasons, in the different places and the respective identification numbers $(N)$

\begin{tabular}{lclllc}
\hline $\begin{array}{l}\text { Comportamento } \\
\text { Behavior }\end{array}$ & $\mathrm{N}$ & $\begin{array}{l}\text { Local } \\
\text { Place }\end{array}$ & Ep 1 & Ep 2 & $\begin{array}{c}\text { Média } \\
\text { Mean }\end{array}$ \\
\hline $\begin{array}{l}\text { Decrescente } \\
\text { Decreasing }\end{array}$ & 1 & S.F.Itabapoana & $2,87^{\mathrm{b}}$ & $2,22^{\mathrm{a}}$ & 2,55 \\
\hline Crescente & 5 & Campos-Carvão & $3,13^{\mathrm{a}}$ & $4,06^{\mathrm{b}}$ & 3,59 \\
Increasing & 9 & Campos-Caxeta & $1,45^{\mathrm{a}}$ & $3,67^{\mathrm{b}}$ & 2,57 \\
& 12 & Campos-Itereré & $1,91^{\mathrm{a}}$ & $2,59^{\mathrm{b}}$ & 2,25 \\
& 6 & B.J.Itabapoana & $1,21^{\mathrm{a}}$ & $2,85^{\mathrm{b}}$ & 2,03 \\
& 3 & S.M.Madalena & $1,08^{\mathrm{a}}$ & $2,05^{\mathrm{b}}$ & 1,57 \\
& 11 & Italva & $1,00^{\mathrm{a}}$ & $1,82^{\mathrm{b}}$ & 1,41 \\
\hline Pequena variação & 2 & Campos-S.Maria & $2,99^{\mathrm{a}}$ & $2,61^{\mathrm{a}}$ & 2,80 \\
Small variation & 8 & S.A.Pádua & $2,29^{\mathrm{a}}$ & $2,55^{\mathrm{a}}$ & 2,42 \\
& 10 & Itaperuna & $1,75^{\mathrm{a}}$ & $2,21^{\mathrm{a}}$ & 1,98 \\
& 7 & Miracema & $1,66^{\mathrm{a}}$ & $1,80^{\mathrm{a}}$ & 1,73 \\
& 4 & S.J.Barra & $0,77^{\mathrm{a}}$ & $0,99^{\mathrm{a}}$ & 0,88 \\
\hline
\end{tabular}

Dentro de cada local, médias seguidas de mesma letra não diferem, pelo teste de $\mathrm{F}$, em nível de $5 \%$ de probabilidade.

Within each place and for each depth, means followed by the same letter do not differ, by F test, at $5 \%$ level of probability. 
ram teores de $\mathrm{S}$ considerados suficientes para atenderem aos requerimentos de bovinos em crescimento e acabamento. As exigências recomendadas pelo NRC (1984), 0,08 a 0,15\% de S na MS, não foram comprovadas neste trabalho, no qual somente os locais Campos-Carvão e Campos-Itereré atendem aos valores mais altos. Quanto ao nível mais baixo de $0,08 \%$ de $\mathrm{S}$ na MS, somente os locais Campos-Caxeta e Bom Jesus do Itabapoana atendem esta exigência no período das chuvas e São João da Barra e São Francisco do Itabapoana, no período seco. O NRC (1996) recomenda $0,15 \%$ de S na MS da ração para bovinos de corte em crescimento e acabamento e vacas em gestação e lactação, com nível máximo tolerável de $0,4 \%$.

Sódio

Os teores de $\mathrm{Na}$ nos solos (Tabela 10) foram extremamente baixos. Detecta-se o teor mais elevado de Na correspondente a $0,23 \mathrm{meq} / 100 \mathrm{~g}$, no solo de

Tabela 9 - Teores médios de S (\% na MS) das forrageiras, nas épocas seca (Ep1) e chuvosa (Ep2) nos diferentes locais, e seus respectivos números de identificação $(\mathrm{N})$

Table 9 - Average Scontents (\% in dry matter) offorages, in the dry(Ep1) and rainy (Ep2) seasons, in the different places and the respective identification numbers $(N)$

\begin{tabular}{lcllcc}
\hline $\begin{array}{l}\text { Comportamento } \\
\text { Behavior }\end{array}$ & $\mathrm{N}$ & $\begin{array}{l}\text { Local } \\
\text { Place }\end{array}$ & Ep 1 & Ep 2 & $\begin{array}{c}\text { Média } \\
\text { Mean }\end{array}$ \\
\hline $\begin{array}{l}\text { Decrescente } \\
\text { Decreasing }\end{array}$ & 1 & S.F.Itabapoana & $0,08^{\mathrm{b}}$ & $0,04^{\mathrm{a}}$ & 0,06 \\
\hline Crescente & 9 & Campos-Caxeta & $0,06^{\mathrm{a}}$ & $0,12^{\mathrm{b}}$ & 0,09 \\
$\begin{array}{l}\text { Increasing } \\
\text { B.J.Itabapoana }\end{array}$ & $0,03^{\mathrm{a}}$ & $0,10^{\mathrm{b}}$ & 0,07 \\
\hline Pequena variação & 4 & S.J.Barra & $0,08^{\mathrm{a}}$ & $0,06^{\mathrm{a}}$ & 0,07 \\
Small variation & 5 & Campos-Carvão & $0,18^{\mathrm{a}}$ & $0,16^{\mathrm{a}}$ & 0,17 \\
& 12 & Campos-Itereré & $0,16^{\mathrm{a}}$ & $0,15^{\mathrm{a}}$ & 0,15 \\
& 3 & S.M.Madalena & $0,07^{\mathrm{a}}$ & $0,05^{\mathrm{a}}$ & 0,06 \\
& 7 & Miracema & $0,06^{\mathrm{a}}$ & $0,04^{\mathrm{a}}$ & 0,05 \\
& 10 & Itaperuna & $0,05^{\mathrm{a}}$ & $0,06^{\mathrm{a}}$ & 0,05 \\
& 8 & S.A.Pádua & $0,05^{\mathrm{a}}$ & $0,04^{\mathrm{a}}$ & 0,04 \\
& 11 & Italva & $0,03^{\mathrm{a}}$ & $0,04^{\mathrm{a}}$ & 0,03 \\
\hline
\end{tabular}

Dentro de cada local, médias seguidas de mesma letra não diferem, pelo teste de $\mathrm{F}$, em nível de $5 \%$ de probabilidade.

Within each place and for each depth, means followed by the same letter do not differ, by F test, at $5 \%$ level of probability.

Tabela 10 - Teores médios de $\mathrm{Na}(\mathrm{meq} / 100 \mathrm{~g})$ nos solos, nas épocas seca (Ep1) e chuvosa (Ep2), nas profundidades de 20 (P1) e $40 \mathrm{~cm}$ (P2), nos diferentes locais e seus respectivos números de identificação $(\mathrm{N})$

Table 10 - Average Na contents (meq/100 g) of soils, in the dry (Ep1) and rainy (Ep2) seasons, in the depths of 20 (1) and $40 \mathrm{~cm}$ (2) in the different places and the respective identification numbers $(N)$

\begin{tabular}{lcccccc}
\hline $\begin{array}{l}\text { Local } \\
\text { Place }\end{array}$ & $\mathrm{N}$ & $\mathrm{Ep1}$ & $\mathrm{Ep2}$ & $\mathrm{P} 1$ & $\mathrm{P} 2$ & $\begin{array}{c}\text { Média } \\
\text { Mean }\end{array}$ \\
\hline B.J.Itabapoana & 6 & 0,04 & 0,04 & 0,03 & 0,03 & 0,03 \\
S.J.Barra & 4 & 0,03 & 0,02 & 0,03 & 0,03 & 0,03 \\
Italva & 11 & 0,07 & 0,07 & 0,07 & 0,07 & 0,07 \\
Campos-Caxeta & 9 & 0,04 & 0,04 & 0,04 & 0,04 & 0,04 \\
Campos-S.Maria & 2 & 0,08 & 0,07 & 0,07 & 0,08 & 0,08 \\
S.F.Itabapoana & 1 & 0,07 & 0,06 & 0,07 & 0,06 & 0,06 \\
S.M.Madalena & 3 & 0,04 & 0,03 & 0,04 & 0,04 & 0,04 \\
S.A.Pádua & 8 & 0,03 & 0,04 & 0,04 & 0,03 & 0,03 \\
Miracema & 7 & 0,03 & 0,02 & 0,03 & 0,02 & 0,02 \\
Campos-Carvão & 5 & 0,24 & 0,23 & 0,25 & 0,22 & 0,23 \\
Campos-Itereré & 12 & 0,05 & 0,09 & 0,07 & 0,07 & 0,07 \\
Itaperuna & 10 & 0,04 & 0,04 & 0,04 & 0,05 & 0,04 \\
\hline
\end{tabular}


Tabela 11 - Teores médios de Na (mg/kg na MS) das forrageiras, nas épocas seca (Ep1) e chuvosa (Ep2), nos diferentes locais, e seus respectivos números de identificação $(\mathrm{N})$

Table 11 - Average Na contents (\% in dry matter) of forages, in the dry (Ep1) and rainy (Ep2) seasons, in the different places and the respective identification numbers $(N)$

\begin{tabular}{lclrrr}
\hline $\begin{array}{l}\text { Comportamento } \\
\text { Behavior }\end{array}$ & $\mathrm{N}$ & $\begin{array}{l}\text { Local } \\
\text { Place }\end{array}$ & Ep 1 & Ep 2 & $\begin{array}{c}\text { Média } \\
\text { Mean }\end{array}$ \\
\hline $\begin{array}{l}\text { Decrescente } \\
\text { Decreasing }\end{array}$ & 3 & S.M.Madalena & $74,70^{\mathrm{b}}$ & $46,30^{\mathrm{a}}$ & 60,00 \\
& 12 & Campos-Itereré & $61,20^{\mathrm{b}}$ & $38,40^{\mathrm{a}}$ & 50,00 \\
\hline Pequena variação & 9 & Campos-Carvão & $63,80^{\mathrm{b}}$ & $18,20^{\mathrm{a}}$ & 41,00 \\
Small variation & 1 & Campos-Caxeta & $6,20^{\mathrm{a}}$ & $0,00^{\mathrm{a}}$ & 3,12 \\
& 8 & S.F. Itabapoana & $4,80^{\mathrm{a}}$ & $0,00^{\mathrm{a}}$ & 2,40 \\
& 2 & S.A.Pádua & $3,80^{\mathrm{a}}$ & $0,00^{\mathrm{a}}$ & 1,90 \\
& 10 & Campos-S.Maria & $3,40^{\mathrm{a}}$ & $0,00^{\mathrm{a}}$ & 1,72 \\
& 4 & Itaperuna & $1,70^{\mathrm{a}}$ & $0,00^{\mathrm{a}}$ & 0,86 \\
& 7 & S.J.Barra & $38,00^{\mathrm{a}}$ & $53,00^{\mathrm{a}}$ & 46,00 \\
& 11 & Miracema & $2,00^{\mathrm{a}}$ & $54,00^{\mathrm{a}}$ & 28,00 \\
& 6 & B.J.Itabapoana & $0,97^{\mathrm{a}}$ & $0,00^{\mathrm{a}}$ & 0,48 \\
& Italva & $0,86^{\mathrm{a}}$ & $0,00^{\mathrm{a}}$ & 0,43 \\
\hline
\end{tabular}

Dentro de cada local, médias seguidas de mesma letra não diferem, pelo teste de $\mathrm{F}$, em nível de $5 \%$ de probabilidade.

Within each place and for each depth, means followed by the same letter do not differ, by $F$ test, at $5 \%$ level of probability.

Campos-Carvão e o teor mais baixo, de 0,02 meq/100 g, em solos de Miracema. Em nível prático, isso significa que as regiões estudadas neste trabalho são como muitas outras regiões do país, onde a pesquisa tem sempre encontrado a deficiência de $\mathrm{Na}$ como a mais comum. Não houve correlação entre os níveis de $\mathrm{Na}$ nos solos e nas forrageiras, $(\mathrm{r}=0,22, \mathrm{P}=0,25)$.

Os teores de $\mathrm{Na}$ das forrageiras foram influenci$\operatorname{ados}(\mathrm{P}<0,01)$ pelo local e pela época do ano, havendo também interação $(\mathrm{P}<0,01)$ de local e época. Em três dos locais estudados, os teores de $\mathrm{Na}$ das forrageiras (Tabela 11) foram maiores $(\mathrm{P}<0,05)$ na época seca do que na chuvosa. Conforme SOUSA et al. (1982), de modo geral, as pastagens brasileiras apresentam baixos níveis de $\mathrm{Na}$, o que também foi encontrado no presente trabalho. Outros pesquisadores como Sutmoller e colaboradores 1966 , citados por CONRAD et al. (1985), afirmaram ser a insuficiência de $\mathrm{Na}$ nas pastagens a deficiência mineral mais comum na Bacia Amazônica. TOKARNIA et al. (1988) encontraram deficiência de Na nas Regiões Norte e CentroOeste do Brasil.

Segundo o NRC (1996), a exigência de Na para bovinos de corte é de 0,06 a $0,08 \%$ da MS; portanto, bovinos criados nas pastagens onde foram feitas análises deste mineral, no presente trabalho, necessitam de suplementação de $\mathrm{Na}$ em todo o período do ano. O maior teor obtido nas forragens representa cerca de $10 \%$ da exigência mínima de bovinos.
Água

Os teores de $\mathrm{Ca}, \mathrm{Pe} \mathrm{Mg}$ na água, nas épocas seca e chuvosa, encontram-se na Tabela 12. Com exceção de Campos-Itereré e Miracema, os níveis médios de P na água situam-se acima da média (0,087 ppm) encontrada em águas de superfície nos Estados Unidos da América (MAYNARD et al., 1979).

Na região de B.J. Itabapoana, ocorreram teores mais elevados de $\mathrm{Ca}$ e $\mathrm{Mg}$ que as médias fornecidas pela Academia Nacional de Ciências dos Estados Unidos (57,1 ppm para Ca e 14,3 ppm para Mg), conforme citado por MAYNARD et al. (1979), embora estes níveis estejam bem abaixo dos níveis máximos informados por aquele órgão (173 ppm de Ca e 137 ppm de Mg). CAVALHEIRO et al. (1987) encontraram 8,78 ppm de Ca e 3,58 ppm de $\mathrm{Mg}$, em águas do Rio Grande do Sul, e VILELA et al. (1987), 9,521 ppm de $\mathrm{Ca}$ e 1,765 ppm de $\mathrm{Mg}$, em águas na bacia hidrográfica do alto Rio São Francisco, Minas Gerais.

Os teores de K, S e Na na água, nas épocas seca e chuvosa, estão na Tabela 13. Os teores de K da água nos locais 4,5 e 9 na época seca e no local 5 na época chuvosa estão bem acima da média (4,3 ppm) relatada por MAYNARD et al. (1979), mas muito abaixo do valor máximo (370 ppm) referido por esses autores. CAVALHEIRO et al. (1987) encontraram 2,07 ppm de K em águas do Rio Grande do Sul e VILELA et al. (1987), 2,207 ppm na água em Minas Gerais, na bacia hidrográfica do alto São Francisco. 
Os níveis de Na na água coletada nos locais 2, 4, 5 e 10 , na época seca, e nos locais 2,5 e 10 , na época chuvosa, estão acima da média (55,1 ppm) relatada por MAYNARD et al. (1979), mas muito abaixo do valor máximo (7500 ppm). CAVALHEIRO et al. (1987) encontraram 5,42 ppm em águas do Rio Grande do Sul e VILELA et al. (1987), 3,774 ppm em águas da região do alto São Francisco, Minas Gerais.

Tabela 12 - Teores de P, Ca e Mg daágua, em mg/L, nas épocas seca e chuvosa, nos diferentes locais e seus respectivos números de identificação $(\mathrm{N})$

Table 12 - $\quad P$, Ca and Mg contents of water, in $\mathrm{mg} / \mathrm{L}$, in the dry (Ep1) and rainy (Ep2) seasons, in the different places and the respective identification numbers $(N)$

\begin{tabular}{|c|c|c|c|c|c|c|c|}
\hline \multirow{3}{*}{$\begin{array}{l}\text { Local } \\
\text { Place }\end{array}$} & \multirow[t]{3}{*}{$\mathrm{N}$} & $\mathrm{P}$ & $\mathrm{Ca}$ & $\mathrm{Mg}$ & $\mathrm{P}$ & $\mathrm{Ca}$ & $\mathrm{Mg}$ \\
\hline & & \multicolumn{3}{|c|}{ Época seca } & \multicolumn{3}{|c|}{ Época chuvosa } \\
\hline & & \multicolumn{3}{|c|}{ Dry season } & \multicolumn{3}{|c|}{ Rainny season } \\
\hline S .F.Itabapoana & 1 & 0,23 & 8,85 & 7,40 & 0,12 & 5,75 & 5,97 \\
\hline Campos-S.Maria & 2 & 0,14 & 28,29 & 18,19 & 0,22 & 29,11 & 16,33 \\
\hline S.M. Madalena & 3 & 0,08 & 1,85 & 1,31 & 0,09 & 0,64 & 0,14 \\
\hline S.J.Barra & 4 & 0,52 & 71,01 & 21,84 & 0,27 & 18,36 & 5,00 \\
\hline Campos-Carvão & 5 & 0,24 & 33,16 & 41,56 & 0,28 & 34,55 & 35,53 \\
\hline B.J.Itabapoana & 6 & 0,14 & 17,25 & 10,19 & 0,20 & 17,15 & 10,79 \\
\hline Miracema & 7 & 0,07 & 2,86 & 1,75 & 0,05 & 2,67 & 1,24 \\
\hline S.A.Pádua & 8 & 0,08 & 1,50 & 0,69 & 0,16 & 9,84 & 6,14 \\
\hline Campos-Caxeta & 9 & 0,32 & 5,79 & 4,33 & 1,54 & 5,21 & 1,09 \\
\hline Itaperuna & 10 & 0,24 & 79,35 & 70,44 & 0,41 & 70,28 & 53,68 \\
\hline Italva & 11 & 0,11 & 2,94 & 1,48 & 0,18 & 4,63 & 2,20 \\
\hline Campos-Itereré & 12 & 0,03 & 1,38 & 0,76 & 0,07 & 1,33 & 0,86 \\
\hline
\end{tabular}

Tabela 13 - Teores de K, S e Na da água, em mg/L, nas épocas seca e chuvosa nos diferentes locais e seus respectivos números de identificação $(\mathrm{N})$

Table 13 - K, S and Na contents of water, in $\mathrm{mg} / \mathrm{L}$, in the dry (Ep1) and rainy (Ep2) seasons, in the different places and the respective identification numbers $(N)$

\begin{tabular}{|c|c|c|c|c|c|c|c|}
\hline \multirow{2}{*}{$\begin{array}{l}\text { Local } \\
\text { Place }\end{array}$} & \multirow[t]{2}{*}{$\mathrm{N}$} & $\mathrm{K}$ & $S$ & \multirow[t]{2}{*}{$\mathrm{Na}$} & \multirow[t]{2}{*}{$\mathrm{K}$} & $S$ & \multirow[b]{2}{*}{$\begin{array}{l}\text { sa } \\
n\end{array}$} \\
\hline & & \multicolumn{2}{|c|}{$\begin{array}{l}\text { Época seca } \\
\text { Dry season }\end{array}$} & & & $\begin{array}{c}\text { Época chuvosa } \\
\text { Rainny season }\end{array}$ & \\
\hline S .F.Itabapoana & 1 & 2,01 & 2,16 & 18,17 & 6,76 & 0,52 & 25,18 \\
\hline Campos-S.Maria & 2 & 11,24 & 2,39 & 122,11 & 5,96 & 1,46 & 108,28 \\
\hline S.M. Madalena & 3 & 3,78 & 0,38 & 6,23 & 0,81 & 0,60 & 3,94 \\
\hline S.J.Barra & 4 & 26,44 & 5,03 & 210,21 & 9,15 & 8,06 & 47,27 \\
\hline Campos-Carvão & 5 & 21,56 & 72,11 & 181,86 & 33,37 & 38,61 & 304,25 \\
\hline B.J.Itabapoana & 6 & 6,31 & 4,86 & 23,66 & 2,94 & 3,84 & 23,64 \\
\hline Miracema & 7 & 1,82 & 1,82 & 7,26 & 0,95 & 1,24 & 4,50 \\
\hline S.A.Pádua & 8 & 0,77 & 0,46 & 3,06 & 2,19 & 2,36 & 13,62 \\
\hline Campos-Caxeta & 9 & 19,64 & 3,49 & 47,71 & 1,40 & 4,19 & 6,27 \\
\hline Itaperuna & 10 & 5,45 & 1,96 & 107,94 & 3,85 & 2,33 & 82,07 \\
\hline Italva & 11 & 1,79 & 1,95 & 5,19 & 1,83 & 1,48 & 8,25 \\
\hline Campos-Itereré & 12 & 1,22 & 2,34 & 6,02 & 1,17 & 1,00 & 7,16 \\
\hline
\end{tabular}




\section{Conclusões}

Houve deficiências de cálcio e fósforo nos solos, em ambas as épocas.

Os teores de $\mathrm{Ca}$ e $\mathrm{Mg}$ das forrageiras foram normais e até elevados em alguns locais.

Observaram-se deficiências de potássio e sódio nos solos, tanto na época seca, como na das chuvas.

Nas forrageiras, ocorreram baixos níveis de enxofre e sódio, nas duas épocas estudadas, não sendo capazes de atender as exigências mínimas de crescimento e engorda dos bovinos.

Os teores de $\mathrm{K}$ das forrageiras foram normais e até elevados em alguns locais.

De modo geral, pode-se afirmar que nenhum elemento mineral comprometeu a qualidade das águas estudadas para sua utilização com os animais domésticos.

\section{Agradecimento}

Ao Prof. Dr. Doracy Pessoa Ramos do Laboratório de Solos, do Centro de Ciências e Tecnologiais Agropecuárias da UENF, pela liberação das fotos da região, e ao Dr. Celso Vainer Manzatto, pela identificação e classificação dos solos.

À ARACRUZ CELULOSE S.A., na pessoa do Dr. Sebastião da Fonseca, pelas facilidades oferecidas nas análises das amostras.

\section{Referências Bibliográficas}

ALBA, J., DAVIS, G.K. 1957. Minerals en la nutrición animal en la America Latina. Turrialba, Costa Rica, 7:16-33.

ALBA, J. 1973. Alimentación del ganado en America Latina. 2.ed. Tallres Gráficos del Editorial Fournier S.A., México. $475 \mathrm{p}$.

CAVALHEIRO, A.C.L., TRINDADE, D.S., WEDERKEHR, N.A. et al. Concentração de alguns minerais em águas do Rio Grande do Sul. In: REUNIÃO ANUALDA SOCIEDADE BRASILEIRA DE ZOOTECNIA, 19, 1987, Brasília, DF. Anais.... Brasília: SBZ, 1987, p.147.

COELHO DA SILVA, J.F. 1. Exigências de macroelementos inorgânicos para bovinos In: SIMPÓSIO INTERNACIONAL SOBRE EXIGÊNCIAS NUTRICIONAIS DE RUMINANTES. Viçosa, MG, 1995. Anais...Viçosa: DZO, 504p. CONRAD, J.H., McDOWELL, L.R., ELLIS, G.L. et al. 1985. Minerais para ruminantes em pastejo em regiões tropicais. Traduzido por EUCLIDES, V.P.B. EMBRAPA-CNPGC, Campo Grande, Mato Grosso do Sul. 91p.
GIOVINI, N. 1943. Estudo clínico da deficiência de fósforo nos bovinos de Minas Gerais. Arq. Bras. Med. Vet., 1:17-26.

GUIMARÃES, P.T.G., FERREIRA, J.G., CARVALHO, J.G. et al. 1980. Adubação de Pastagens.Inf. Agropec., 6(70):34-52.

JARDIM, W.R., PEIXOTO, A.M., MORAES, C.L. 1962. Composição mineral de pastagens na região de Barretos no Brasil Central. Boletim Técnico Científico da Escola Superior de Agricultura Luiz de Queiroz, 11:11.

MAYNARD, L.A., LOSLI, J.K., HINTZ, H.F. et al. 1979. Animal nutrition. 7.ed. Mc Graw-Hill Books Company, NY. $620 \mathrm{p}$.

NATIONAL RESEARCH COUNCIL - NRC. 1984. Nutrient requirements of beef cattle. 6 . ed. Washigton: National Academy of Science. 182p.

NATIONAL RESEARCH COUNCIL - NRC. 1996. Nutrient requirements of beef catlle. 7.ed. Washigton: National Academy of Science. 242p.

POSSENTI, R.A., LOBÃO, A.O., RIBEIRO, W.R. 1992. Determinações minerais em forragens e tecidos de bovinos. Bol. Ind. Anim., 49(2):131-144.

SAS - Statistical Analisys System.1990. User's guide. SAS Institute Inc. Cary, NC. 142p.

SHIRLEY, R.L., MARIANTE, A.. 1976. Enxofre na nutrição de ruminantes. In: SIMPÓSIO LATINO AMERICANO SOBRE PESQUISAS EM NUTRIÇÃO MINERAL DE RUMINANTES EM PASTAGENS, Belo Horizonte, 1976.Anais... Belo Horizonte, 1976, p.130.

SILVA, D.J. 1990. Análise de alimentos (métodos químicos e biológicos). Viçosa, MG: UFV. $165 \mathrm{p}$.

SOUSA, J.C., CONRAD, J.H., MOTT, G.O. et al. 1982. Interrelações entre minerais no solo, plantas forrageiras e tecido animal. 4- Zinco, magnésio, sódio e potássio. Pesq. Agropec. Bras., 17(1):11-20.

SUTMÖLLER, P., ABREU, A.V., VAN DER GRIFT, J. et al. 1966. Mineral imbalances in cattle in the Amazon Valley. Amsterdan, Dept. of Agric. Res. of the Royal Trop. Inst. 133p. Comm. nº53.

TEIXEIRA, T., CAMPOS, J., BRAGA, J.M. et al. 1971. Deficiências de fósforo, cobre e cobalto em pastagens do município de Morrinhos, Goiás. Experientiae, 12(3):63-87.

THEILLER, A., GREEN, H.H., DUTOIT, P.J. 1924. Phosphorus in the livestock industry. Union South Africa Dept. Agric. J. Barbados, (8):460-504.

VILELA, H., SILVA, J.F.C., PAULINELLI, M.T. et al. Conteúdo em minerais das águas de superfície da bacia hidrográfica do Alto São Francisco do Estado de Minas Gerais. In: REUNIÃO ANUAL DA SOCIEDADE BRASILEIRA DEZOOTECNIA, 24, Brasília 1987. Anais... Brasília, 1987. p.149.
Recebido em: 30/03/98 Aceito em: 27/09/99 